\title{
Elektrik Akımı Destekli Sinterleme Yöntemi İle Üretilen Stellite 21 Süperalaşımının Sıcak Korozyon Özellikleri
}

\author{
Nuri Ergin ${ }^{*}$, Özkan Özdemir ${ }^{2}$, Ahmet Yiğit Özer ${ }^{3}$ \\ 1* Sakarya Uygulamalı Bilimler Üniversitesi, Teknoloji Fakültesi, Metalurji ve Malzeme Mühendisliği Bölümü, Sakarya, Türkiye, (ORCID: 0000-0001-9025-9419), \\ nergin@subu.edu.tr \\ ${ }^{2}$ Sakarya Uygulamalı Bilimler Üniversitesi, Teknoloji Fakültesi, Metalurji ve Malzeme Mühendisliği Bölümü, Sakarya, Türkiye (ORCID: 0000-0003-2366-8196), \\ oozdemir@subu.edu.tr \\ ${ }^{3}$ Sakarya Uygulamalı Bilimler Üniversitesi, Lisansüstü Eğitim Enstitüsü, İmalat Mühendisliği Bölümü, Sakarya, Türkiye (ORCID: 0000-0002-4336-2314), \\ y145047006@subu.edu.tr
}

(1st International Conference on Applied Engineering and Natural Sciences ICAENS 2021, November 1-3, 2021)

(DOI: 10.31590/ejosat.1013395)

ATIF/REFERENCE: Ergin, N., Özdemir, Ö. \& Özer, A. Y. (2021). Elektrik Akımı Destekli Sinterleme Yöntemi İle Üretilen Stellite 21 Süperalaşımının Sıcak Korozyon Özellikleri. Avrupa Bilim ve Teknoloji Dergisi, (28), 1185-1189.

Öz

Bu çalışmada Stellite 21 süper alaşımı, uygun kompozisyonda hazırlanarak homojen karıştırma sonrası elde edilen toz karışım kullanılmak suretiyle, elektrik akımı destekli sinterleme yöntemi ile üretilmiş̧ir. Daha sonra numunelerin sertlik, mukavemet ve yüksek sıcaklık özellikleri gibi özelliklerini geliştirmek için ısıl işlem uygulanmıştır. Üretilen malzemenin; mikroyapı görüntüleri taramalı elektron mikroskobuyla; faz analizleri, $\mathrm{x}$-ışınları difraksiyon analizi ve elementel analiz incelemesi yöntemiyle belirlenmiştir. Ayrıca korozyon özellikleri sıcak korozyon çalışmaları ile tespit edilmiştir.

\section{Hot Corrosion Properties of Stellite 21 Super Alloy Produced By Electric Current Assisted Sintering}

\begin{abstract}
In this study, Stellite 21 alloy is produced with a resistance sintering method by using powder obtained from homogeneous mixing with appropriate composition. Then, the sample was exposed to heat treatment in order to improve the properties of the Stellite 21 super alloy such as strength, hardness and its high temperature properties. Microstructure images of the produced material were determined by scanning electron microscope, their phase analyses with x-ray diffraction analysis and elemental analysis methods. Also, corrosion qualities were determined by hot corrosion practices..
\end{abstract}

Keywords: Superalloy, Stellite 21, Electric Current Activated Sintering.

*Sorumlu Yazar: nergin@subu.edu.tr 


\section{Giriş}

Süper alaşımlar; yüksek sıcaklıklarda kararlılığını koruyabilen, mükemmel oksidasyon, korozyon ve sürünme direnci sergileyen, ergime sicaklığının 0.8 katına kadar kullanılabilen, metalurjik olarak demir, nikel veya kobalt matrisinden oluşup, matris içerisinde karbür veya intermetalik fazlar ve düşük miktarda alaşım elementleri içeren yüksek sıcaklık malzemeleridir (Çay ve Ozan, 2005; Bernardo, Eberle ve Ristow, 2008; Chen ve Liao, 2003). Bu malzemeler; seramik malzemelerin gevrek karakterlerinden kaynaklanan düşük tokluk özelliklerini, metalik malzemelerin yüksek sıcaklıklardaki düşük oksidasyon ve düşük mukavemet özelliklerini iyileştirmek amacıyla geliştirilmiştir. Bu malzeme grubu içerisinde kobalt içeriği ile ön planda olan alaşımlar yani kobalt esasl süperalaşımlar, yüksek sıcaklıklardaki statik gerilmeler altında göstermiş oldukları yüksek mukavim özellikleri ile yüksek sıcaklık yapı malzemesi olarak kullanılmaktadır. Kobalt esaslı süperalaşımların tercih edilme sebebi, diğer süperalaşımlarla karşılaştırıldığında daha yüksek ergime derecesine sahip olması, dolayısıyla yüksek sıcaklık mekanik özelliklerinin daha iyi olması ve ihtiva ettiği yüksek krom içeriği sayesinde mükemmel sıcak korozyon dayanımı sergilemesidir (Reed, 2006).

Kobalt esaslı süperalaşımların bir türü olan Stellite 21 alaşımları mekanik ve tribolojik özelliklerin kombinasyonunu hem yüksek sıcaklıklarda hem de oda sıcaklığında sağlamakta olup, mükemmel oksidasyon ve korozyon özellikleri sergilemektedir. Stellite 21 süperalaşımının özelliklerini kobaltın düşük istiflenme enerjisi ve sert karbürler önemli ölçüde etkilemektedir. Mo, W ve Cr gibi katı eriyik oluşturucu elementler mukavemetin artmasına katkı sağlarken, karbür çökeltileri ana güçlendirme mekanizmasını oluşturmaktadır. Stellite 21 süperalaşımları sahip oldukları özellikleri sayesinde gaz türbinlerinin yüksek sıcaklığa maruz kalan kısımlarında, nükleer reaktörlerde, türbin kanatları, yanma odaları, afterburner parçalarında, fırın muffle ve yüksek sıcaklık fırınlarında kritik nokta gömleklerinde ve endüstriyel fırınlar gibi çeşitli uygulamalarda kullanım alanı bulmaktadır (Radu, $\mathrm{Li}$ ve Llewellyn, 2004).

Süperalaşımların üretiminde genel olarak ergitme-döküm yöntemleri tercih edilmesine rağmen son yıllarda toz metalürjisi teknikleri üzerine yoğun çalışmalar yapılmaktadır. Geleneksel toz metalurjisi yöntemlerinden daha ziyade spark plazma sinterlemesi (SPS), plazma aktivasyon sinterlemesi (PAS) gibi alternatif teknikler tercih edilmektedir. $\mathrm{Bu}$ alternatif toz metalurjisi tekniklerinden biri de elektrik akım destekli sinterleme yöntemi (ECAS) olup; kısa işlem süresinde, düşük sinterleme sıcaklığında ve daha yüksek ısıtma hızında sinter bağları oluşturmayı sağlayan yeni bir sentezleme yaklaşımıdır. Sinterleme işlemi, şekillendirme işlemi yapılmadan kalıp içine alınan toz karışım veya ön şekillendirme işlemi gerçekleştirilip tablet haline getirilmiş numuneler üzerinden elektrik akımının geçirilmesiyle oluşan Joule etkisinden yararlanılarak yapılmaktadır (Grasso, Sakka ve Maizza, 2009).

Bu çalışmada, Stellite 21 süperalaşımı elektrik akım destekli sinterleme yöntemi (ECAS) ile üretilmiş, üretim sonrası 1sıl işlem uygulanarak Taramalı Elektron Mikroskobu (SEM) ile mikroyapısı, XRD analizi ile faz yapısı ve sicak korozyon çalışmaları ile korozyon özellikleri belirlenmiştir.

\section{Materyal ve Metot}

Stellite 21 süperalaşımının üretiminde başlangıç malzemesi olarak Ni (\%99.8 saflık, 3-7 $\mu \mathrm{m})$, Fe (\%99 saflık, 6-8 $\mu \mathrm{m}), \mathrm{Cr}$

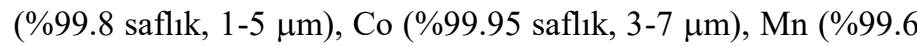
saflık, $<10 \mu \mathrm{m})$ ve Si $(\% 99.9$ saflık, $1-5 \mu \mathrm{m})$ tozları kullanılmıştır. Elementel tozlardan stokiometrik bileşim oranına göre hazırlanan toz karışım gezegensel bilyalı değirmende toz/ağırlık oranı 1:20 olacak şekilde, 30 dakika süre ve $600 \mathrm{rpm}$ hızda homojen olarak karıştırılmıştır. Hazırlanan karışımın ön şekillendirme işleminin gerçekleştirilmesi ve elektrik akımının numune üzerinden geçirilmesi için üretim öncesi nihai şekli belirlenen numunelere uygun olarak hazırlanan kalıplar yüzey pürüzlülüğü minimuma indirgenerek bor nitrür yağlayıcılar ile yağlanmıştır. Tek eksenli hidrolik pres kullanılarak $200 \mathrm{MPa}$ basınç altında şekillendirme işlemi yapılan numuneler kalıp içerisinden çıkarılmadan 1004580 amper aralığında 7 dakikada ECAS tekniği kullanılarak üretilmiştir. Proses süresince akım tipi olarak tam doğrultulmuş DC kullanılmış ve işlem sonunda $20 \mathrm{~mm}$ çap ve $5 \mathrm{~mm}$ yüksekliğe sahip numuneler elde edilmiştir.

Üretimi gerçekleştirilen Stellite 21 süperalaşımının mekanik özelliklerini geliştirmek, dolayısıyla optimum özelliklere ulaşmak amacıyla numuneler birkaç adımdan meydana gelen 1sıl işleme tabi tutulmuştur. Numuneler öncelikle $1200^{\circ} \mathrm{C}$ sicaklıkta 4 saat firında bekletilmiş ve bu süre sonunda suda soğutulmuştur. Daha sonra yaşlandırma işlemini gerçekleştirmek amacıyla $815^{\circ} \mathrm{C}$ 'de 4 saat ve akabinde $715^{\circ} \mathrm{C}$ 'de 30 dakika firında bekletilmiş ve $\% 10$ oranında şekil değişimi olana kadar sıcak dövme işlemi gerçekleştirilmiştir. Üretimi gerçekleştirilip 1sıl işlemi yapılan numuneler, standart numune hazırlama yöntemlerine uygun olarak 2500 gridlik zımpara seviyesine kadar zımparalanmış ve $0,3 \mu \mathrm{m}$ alümina ile parlatılmıştır. Mikroyapıların açığa çıkması için yapılan dağlama işlemi Marbles reaktifi $(50 \mathrm{ml} \mathrm{su}, 50 \mathrm{ml} \mathrm{HCl}$, 10 gr $\mathrm{CuSO}_{4}$ ) kullanılarak gerçekleştirilmiştir.

Numunelerin mikroyapı ve faz analizleri sonrası sicak korozyon özelliklerini belirlemek amaciyla Stellite 21 süper alaşımının kullanım alanları da göz önünde bulundurularak bu alaşımların servis şartları simule edilip $\% 60 \mathrm{~V}_{2} \mathrm{O}_{5}, \% 40 \mathrm{Na}_{2} \mathrm{SO}_{4}$ ve $\% 90 \mathrm{Na}_{2} \mathrm{SO}_{4}, \% 5 \mathrm{~V}_{2} \mathrm{O}_{5}, \% 5 \mathrm{NaCl}$ iki farklı korozif tuz ortamındaki korozyon davranışları incelenmiştir. $\mathrm{Bu}$ korozif tuz karışım içerisinde gömülen numuneler $15^{\circ} \mathrm{C} / \mathrm{dk}$ 1sıtma hızında 550,600 ve $650^{\circ} \mathrm{C}$ sıcaklıklara kadar ısıtılmıs 12,36 ve 60 saat süreyle açık atmosferli kül firında bekletildikten sonra oda sıcaklığına soğutulmuştur. Daha sonra numune yüzeyinde çöken tuz kalıntılarını uzaklaştırmak için saf su ile yıkanmış ve kurutulmuştur. Korozyon hızı, ağırlık değişiminin yüzey alanına oranı esas alınarak kütle kaybından hesaplanmıştır. Numunelerin ağırlık ölçümleri 0,00001 hassasiyete sahip elektronik terazi ile gerçekleştirilmiştir.

\section{Araştırma Sonuçları ve Tartışma}

Stokiometrik bileşim oranına göre hazırlanan toz karışım $200 \mathrm{MPa}$ basınç altında, 100-4580A akım aralığında 7 dakika sabit sürede bekletilerek elektrik akımı destekli sinterleme yöntemi ile üretilmiştir. Üretimi gerçekleştirilen numunelerin özelliklerini iyileştirmek amacıyla termal ve mekanik işlemlerden oluşan kompleks bir ısıl işlem prosesi uygulanmıştır. Nihai ürün olarak değerlendirilen numuneler Marbles reaktifi ile dağlanmış ve mikroyapı incelemeleri gerçekleştirilmiştir. 
Mikroyapı incelemeleri SEM analizi ile yapılmış ve analiz sonuçları Şekil 1'de verilmiştir. Voort, Manılova ve Lucas (2004), süper alaşımların genel itibari ile metalografik olarak hazırlanmasının oldukça güç olduğunu, ihtiva ettiği karbürler ve intermetalik fazlar sebebiyle kesme, zımparalama ve parlatma işlemleri esnasında yüzeyde derin çizikler oluşacağını vurgulamışlardır. Ayrıca yüksek korozyon direncine sahip olan süperalaşımların dağlama işleminin dakikalar mertebesinde sürmesi bölgesel olarak aşırı yanmaların gerçekleşmesi nedeniyle sağlıklı bir dağlamanın yapılamayacağı bildirmişılerdir. Yapılan bu çalışmada standart numune hazırlama işlemleri ile yüzey açı̆̆a çıkarılmış, Marbles reaktifi ile dağlama işlemi sorunsuz olarak gerçekleştirilmiştir. Dolayısıyla birçok çalışmada olduğu gibi kırık yüzey incelemesine gerek duyulmamıştır. Numunenin faz incelemelerinden belirlenen üretim şartlarında faz dönüşümünün tamamlandığı, homojen ve porozitesiz oldukça yüksek yoğunluklu bir yapının elde edildiği görülmektedir.

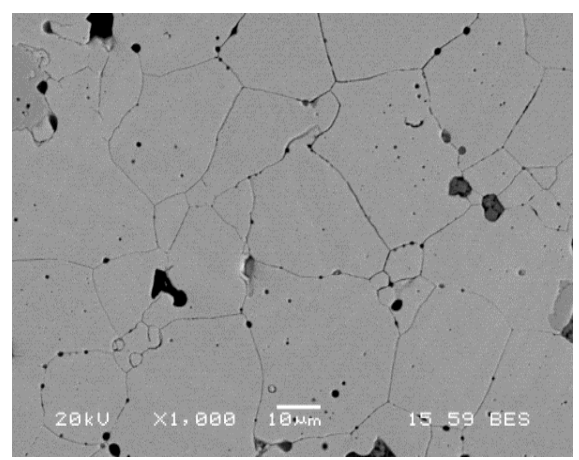

Şekil 1. Üretilip 1sıl işlemi gerçekleştirilmiş numunenin SEM görüntüsü (Dağlayıc1: Marbles reaktifi)

Üretilip, 1sıl işlem prosesleri gerçekleştirilen numunelerin faz dağılımlarının belirlenmesi ve içeriğinde bulunup malzemeye belirli özellik katan elementlerin mikroyapı içindeki dağılımlarının tespit edilmesi için SEM noktasal elementel analiz incelemesi yapılmıştır. SEM-EDS analiz sonuçları Şekil 2'de verilmiştir. Stellite 21 numunesinin 3 farklı bölgesinden alınan EDS sonuçlarına göre matris yapısının Co ağırlıklı olduğu, yapı içerisindeki kimyasal kompozisyona uygun olarak bazı bölgelerde $\mathrm{Cr}$ içeriğinin yoğun olup; Mo, Fe, Mn ve Si içerikleri tespit edilmiştir. Stellite 21 süper alaşımının içeriğine bakıldı ğında $\% 60,25 \mathrm{Co}, \% 27 \mathrm{Cr}, \% 5.5 \mathrm{Mo}, \% 2 \mathrm{Ni}, \% 3 \mathrm{Fe}, \% 0.25$ C, \%1 Mn ve Si oluşmaktadır. Dolayısıyla EDS analizlerinden genel olarak hedeflenen kimyasal kompozisyona ulaşıldığ belirlenmiştir.
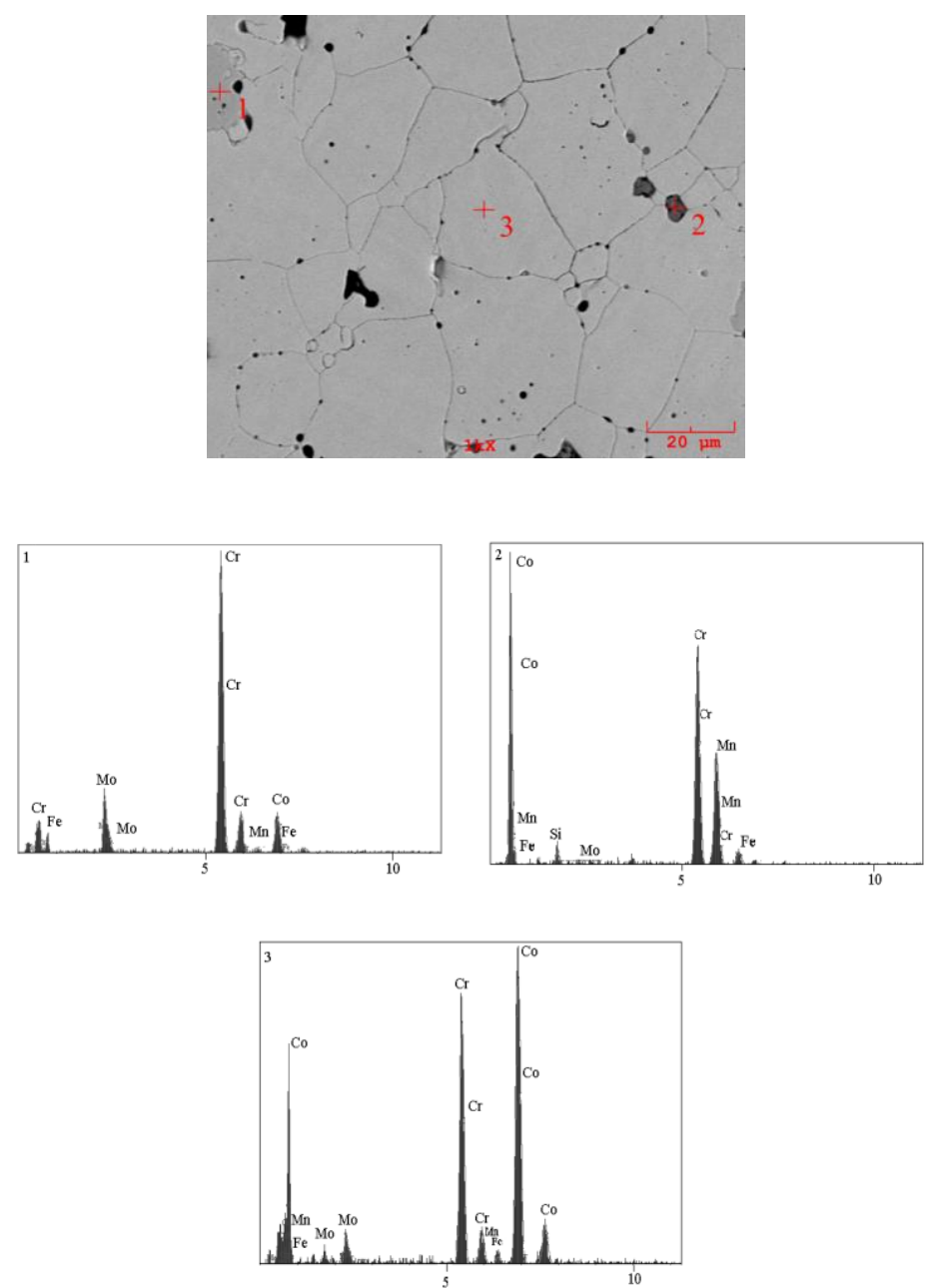

Şekil 2. Üretilip 1sıl işlemi gerçekleştirilmiş numunenin SEM-EDS analizi

Üretimi gerçekleştirilen ve 1sıl işlemi yapılan Stellite 21 numunesinde oluşan fazları tespit etmek amacıyla X-1şınları difraksiyon analizi yapılmış ve XRD paternleri Şekil 3'de verilmiştir. Numunelerin XRD paternlerinden $\alpha$ : M23C6, $\beta$ : Co3Mo, $\varepsilon$ : Co (hcp), $\mu$ : Co7Mo6, $\gamma$ : Co (fcc), $\delta$ : NiCrCoMo fazları tespit edilmiştir. Aslan (2019), Stellite 6 ve 12 süperalaşımlarının kayma aşınması davranışlarını incelemiş ve yapmış olduğu çalışmada elde ettiği fazlar ile bu çalışmada tespit edilen fazların benzer olduğu görülmüştür. Motallebzadeh (2015), Alaşımlı ve Karbür Takviyeli Stellite 12 Süperalaşımını kaplama malzemesi olarak kullanmış ve yüksek sıcaklıkta aşınma performansını değerlendirmiştir. Bu çalışmada rapor edilen XRD paternleri de yapmış olduğumuz çalışmayı destekler niteliktedir. Wu vd. (2019), yaşlanma işlemi süresince Stellite/Çelik sert dolgu ara yüzeyinin termal kararlılığını incelemiş ve Rong, Jianhua, Qunli, Matthew ve Rachel (2015), düşük karbonlu Stellite alaşımlarının aşınma ve korozyon davranışları üzerine molibdenin etkisini araştırmışlardır. Birbirinden farklı olarak gerçekleştirilen her iki çalışmanın da XRD sonuçlarından benzer faz yapılarının belirlendiği görülmüştür. Dolayısıyla elde edilen XRD paternlerinin literatürle uyumlu olduğu söylenebilir. 


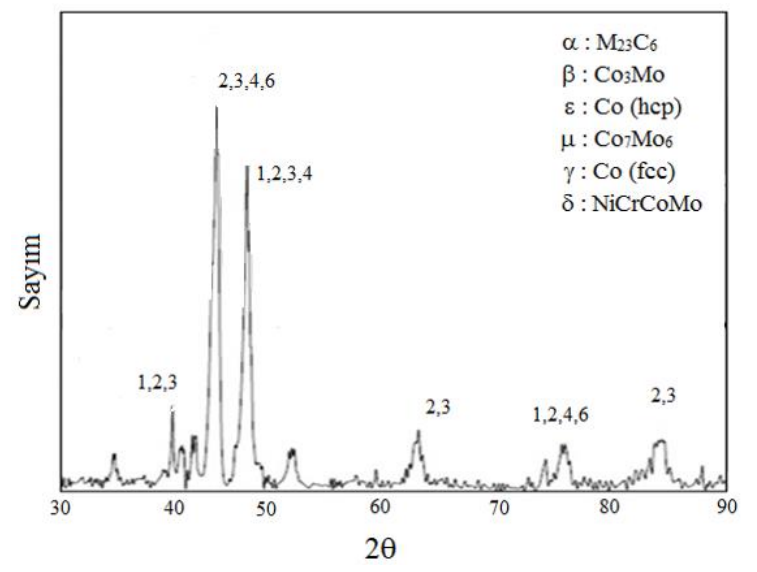

Şekil 3. Numunelerin 1sıl işlem sonrası elde edilen XRD paternleri

Stellite 21 süperalaşımı genel itibari ile nükleer endüstri için aday malzemeler olarak değerlendirilmesine rağmen, günümüzde kağıt imalatı, petrol işleme, ilaç endüstrisi, havacılık, kimya sektörü gibi farklı endüstriyel alanlarda kullanılmaktadır (Reed, 2006). Stellite 21 süperalaşımının kullanıldı ̆̆ 1 bir diğer alan da jet motorlarının yapısal kısımlarının imalatıdır. Jet motorları emilen havanın sıkıştırılması, sonrasında yanma odasında yakıt ile karıştırılarak yakılması ve burada elde edilen yüksek basınç ve sıcaklıktaki gazların türbinler vasıtasıyla mekanik güce dönüştürülmesi ile çalışmaktadır (Torak, 2007). Dolayısıyla servis şartlarına bağlı olarak türbin motorlarının yakıtlarında bulunan $\mathrm{Na}, \mathrm{S}$ ve $\mathrm{V}$ gibi saflığı bozan empüriteler düşük sıcaklıklarda eriyerek Na2SO4 ve V2O5 tuzlarını oluşturmak suretiyle sicak korozyon için kuvvetli bir korozif ortam meydana getirmektedir (Habıbı, 2014). Bu çalışmada, jet türbin motorlarının yapımında kullanılması planlanan Stellite 21 numunesinin sıcak korozyon davranışlarını belirlemek amacıyla jet motorlarının çalışma şartları simüle edilerek iki farklı korozif ortam (I. ortam $\% 60$ V2O5, \%40 Na2SO4 ve II. ortam \%90 $\mathrm{Na} 2 \mathrm{SO} 4, \% 5 \mathrm{~V} 2 \mathrm{O} 5, \% 5 \mathrm{NaCl}$ ) hazırlanmıștır. Stellite 21 süper alaşımının sıcak korozyon deneyleri 550,600 ve $650^{\circ} \mathrm{C}$ ' de 12,36 ve 60 saat $15^{\circ} \mathrm{C} / \mathrm{dk}$ isıtma hızında açık atmosferli kül firın içerisinde gerçekleştirilmiştir.

Bir metalin oksijene afinitesi, oksidin oluşması ile ortaya çıkan serbest enerjisindeki azalma ile belirlenmektedir. Dolayısıyla serbest enerji değeri negatif olan metal daha önce oksitlenmektedir. Chen vd. (2019), Stellite 21 süper alaşımının ana elementleri olan $\mathrm{Co}, \mathrm{Cr}$ ve $\mathrm{Mo}$ 'in $700^{\circ} \mathrm{C}$ 'de standart serbest enerji değerlerini sırasıyla yaklaşık olarak $-330,-580,-500 \mathrm{~kJ} / \mathrm{mol}$ olduğunu tespit etmişler ve serbest enerjisi negatif olan Cr'un oksit oluşturma eğilimi alaşımdaki diğer elementlere göre daha yüksek olduğunu belirtmişlerdir. Oluşan oksit tabakasının koruyucu özellikte olup olmadığı tespit edilirken PillingBedworth oranının veya metal oksit hacim oranının etkili olduğunu işaret etmişlerdir. Yaptıkları çalışmada $650^{\circ} \mathrm{C}$ 'de malzeme yüzeyinde oluşan oksit tabakasında dökülmeler gözlemişler ve burada oksitler, difüzyon kontrolünde olduğundan parabolik olarak büyüdüğünü bildirmişlerdir. Necina ve Pabst (2019), çoğunlukla metal iyonlarının yarıçaplarının oksijen iyonunun yarıçapından daha küçük olması sebebiyle metal iyonlarının dışa yayınımının daha hızlı olduğunu belirlemişlerdir. Orru, Gullion ve Chaim (2018), ise Stellite 21 süperalaşımında Cr iyonunun (+3) yarıçapı $0,63^{\circ} \mathrm{A}$, Co iyonunun $(+3)$ yarıçapı $0,72^{\circ} \mathrm{A}, \mathrm{Fe}$ (II) iyonunun yarıçap $10,74^{\circ} \mathrm{A}$ ve $\mathrm{O}$ iyonunun $(+2)$ yarıçap $1,32^{\circ} \mathrm{A}$ olduğunu tespit etmişlerdir. Değerler göz önüne alındığında Cr iyonu oksijene kıyasla daha hızlı dışa doğru difüze olacağını bildirmişlerdir. $\mathrm{Bu}$ çalışmada, Stellite 21 süper alaşımının kullanım alanları da göz önünde bulundurularak $\% 60 \mathrm{~V}_{2} \mathrm{O}_{5}, \% 40 \mathrm{Na}_{2} \mathrm{SO}_{4}$ ve $\% 90 \mathrm{Na}_{2} \mathrm{SO}_{4}, \% 5 \mathrm{~V}_{2} \mathrm{O}_{5}, \% 5 \mathrm{NaCl}$ iki farklı korozif tuz ortamındaki korozyon davranışları incelenmiştir. Yüksek sıcaklık korozyonu 4 aşamadan oluşmakta olup ilk aşamada oksit tabakasının bir miktar büyümesi ve ardından bölgesel olarak gerçekleşen parçalanmalardan dolayı malzeme yüzeyinde pürüzlülükler olması beklenmektedir. İkinci aşamada oksit tabakasının parçalanmasının devam etmesiyle $\mathrm{Cr}$ tüketimi başlamış olup, üçüncü aşamada $\mathrm{Cr}$ miktarı minimum seviyelere gelmiştir. Oldukça azalan Cr elementi gözenekli bir yapı oluşturmaktadır. Son aşamada ise dökülmeler ile birlikte malzemedeki kayıplar ortaya çıkmaktadır (Salehnasab, Poursaeıd1, Mortazavı ve Forkhıan, 2016).
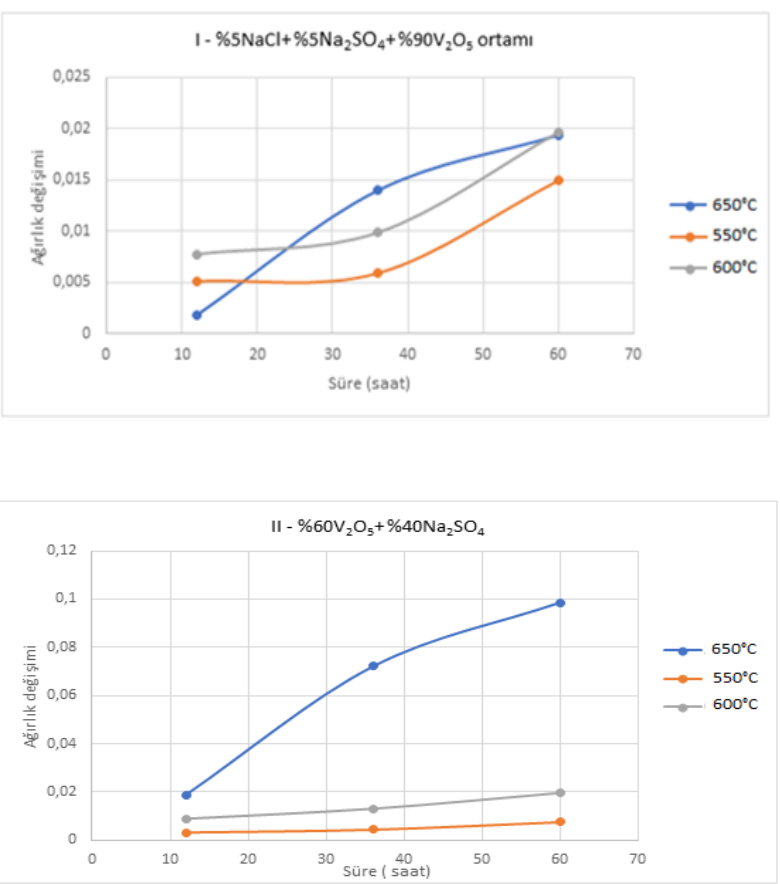

Şekil 4. Stellite 21 süper alaşımının süre ve sıcaklığa bağlı ağırlık değişimleri $\left(\mathrm{g} / \mathrm{mm}^{2}\right)$

Numunelerin ağırlık değişimlerindeki artışın sıcaklık ve sürenin artışıyla birlikte arttığı ve tüm sıcaklıklarda sıcak korozyona maruz kalmış numunelerde herhangi bir dökülmenin olmadığı gözlenmiştir. Sicaklık ve sürenin artışı ile beraber numunelerdeki ağırlıkların parabolik değişime uygun olarak değiştiği görülmüştür. Her iki korozif ortamda da yapılan sıcak korozyon çalışmaları sonrası Stellite 21 alaşımının parabolik hız sabiti değerlerinden elde edilen grafikler şekil 5' de verilmiştir. Parabolik hız sabiti ile malzemenin korozyon dayanımı arasında ters orantı olduğu bilinmektedir. Dolayısıyla $\mathrm{NaCl}+\mathrm{Na}_{2} \mathrm{SO}_{4}+\mathrm{V}_{2} \mathrm{O}_{5}$ ortamında stellite $21^{\prime}$ in $650^{\circ} \mathrm{C}^{\prime}$ deki korozyon davranışı en kötüsüdür. $550^{\circ} \mathrm{C}$ ' deki korozyon davranışı ise en iyidir. $\mathrm{Na}_{2} \mathrm{SO}_{4}+\mathrm{V}_{2} \mathrm{O}_{5}$ ortaminda yine $650^{\circ} \mathrm{C}$ ' de korozyon davranışı en kötüyken, $550^{\circ} \mathrm{C}^{\prime}$ de korozyon davranışı en iyi durumdadir. 

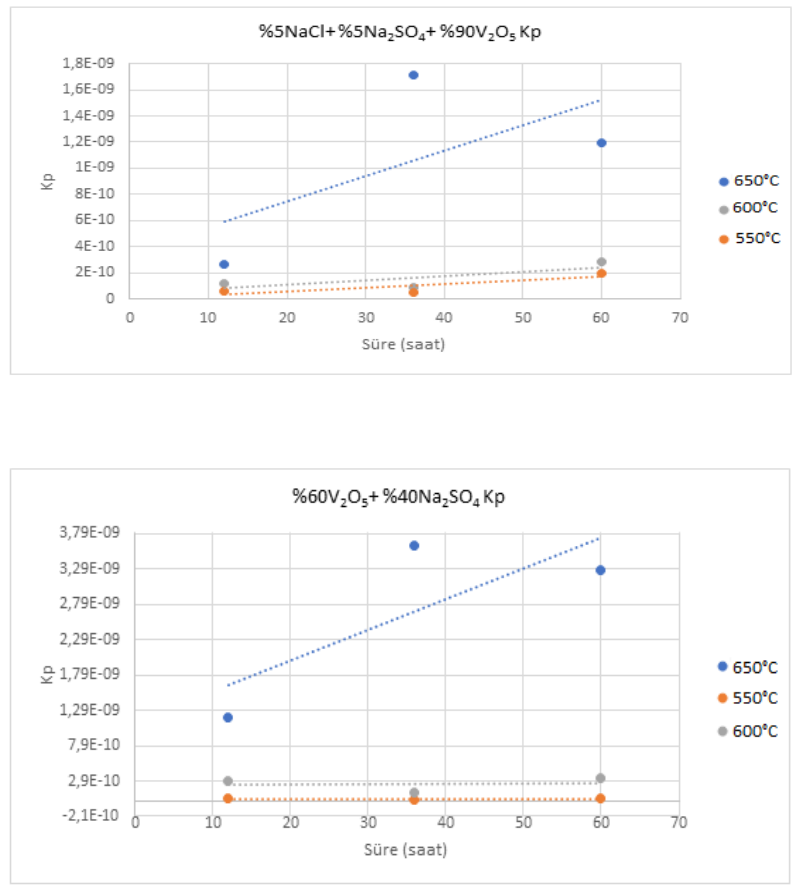

Şekil 5. Stellite 21 parabolik hız sabitlerine ait grafikler

\section{Sonuç}

Bu çalışmada, Stellite 21 süper alaşımını meydana getiren elementel tozlar $600 \mathrm{rpm}$ hızda 6 saat süreyle karıştıııldıktan sonra 200MPa basınç, 0-4580A akımda 7 dakikada elektrik akımı destekli sinterleme yöntemiyle üretilmiştir. Üretim sonrası mekanik özelliklerin geliştirmesi amacıyla yaşlandırma ve sıcak dövme isıl işlemleri uygulanmıştır. Yapılan faz analizlerinden $\alpha$, $\beta$, y ve $\varepsilon$ fazları tespit edilirken M23C6 faz piki de XRD paternlerinde gözlemlenmiştir. Numunelerin korozyon davranışlarını belirlemek için I. ortam $\% 5 \mathrm{NaCl}+\% 5 \mathrm{Na}_{2} \mathrm{SO}_{4}+$ $\% 90 \mathrm{~V}_{2} \mathrm{O}_{5}$ II. ortam $\% 60 \mathrm{~V}_{2} \mathrm{O}_{5}+\% 40 \mathrm{Na}_{2} \mathrm{SO}_{4}$ iki farklı ortamda 12,36 ve 60 saat sürede sıcak korozyon çalışmaları yapılmıştır. Bu ortamlarda yapılan sıcak korozyon sonrasında Stellite 21' e ait parabolik hiz sabitleri(Kp) I. ortamda sirasiyla; $550^{\circ} \mathrm{C}^{\prime}$ de $36,1 \times 10^{-9} \mathrm{~g}^{2} \mathrm{~cm}^{-4} \mathrm{~s}^{2} ; \quad 600^{\circ} \mathrm{C}^{\prime} \mathrm{de} \quad 36,51 \times 10^{-11} \mathrm{~g}^{2} \mathrm{~cm}^{-4} \mathrm{~s}^{2} ; \quad 650^{\circ} \mathrm{C}^{\prime}$ de $37,5 \times 10^{-9} \mathrm{~g}^{2} \mathrm{~cm}^{-4} \mathrm{~s}^{2}$, dir. II. ortamda ise; $550^{\circ} \mathrm{C}^{\prime}$ de $36,3 \times 10^{-9} \mathrm{~g}^{2} \mathrm{~cm}^{-}$ ${ }^{4} \mathrm{~s}^{2} ; 600^{\circ} \mathrm{C}^{\prime}$ de $36,12 \times 10^{-10} \mathrm{~g}^{2} \mathrm{~cm}^{-4} \mathrm{~s}^{2} ; 650^{\circ} \mathrm{C}^{\prime}$ de $36,1 \times 10^{-10} \mathrm{~g}^{2} \mathrm{~cm}^{-4} \mathrm{~s}^{2}$ olarak tespit edilmiştir.

\section{Kaynakça}

Aslan, O. (2019). Stellite 6 ve stellite 21 alaşımlarının darbeli kayma aşınma performanslarının incelenmesi. Yüksek Lisans Tezi, İstanbul Teknik Üniversitesi, Fen Bilimleri Enstitüsü.

Bernardo N., Eberle T., Ristow W. (2008) MIM processing and plasma sintering of nickel base superalloys for aerospace and automotive applications. Powder Metallurgy, 51, 2-107.

Chen, C., Liang, T., Gao Y., Chen, X., Man, Q., Zhang X., Zeng, J. Ji, V. (2019). Effect of scandia content on the hot corrosion behavior of $\mathrm{Sc} 2 \mathrm{O} 3$ and $\mathrm{Y} 2 \mathrm{O} 3$ co-doped $\mathrm{ZrO} 2$ in $\mathrm{Na} 2 \mathrm{SO} 4+\mathrm{V} 2 \mathrm{O} 5$ molten salts at $1000{ }^{\circ} \mathrm{C}$. Corrosion Sicence, 158 .

Chen Y.C. ve Liao Y.S. (2003). Study on wear mechanisms in drilling of Inconel 718 superalloy. Journal of Materials Processing Technology, 140, 269-273.

Çay V. ve Ozan Ş. (2005). Süper alaşımlar ve Uygulama Alanları, Doğu Anadolu Bölgesi Araştırmaları.

e-ISSN: 2148-2683
Habıbı, M.H. (2014). Hot corrosion behaviour of new candidates for thermal barrier coatings application in türbine simulated environments. Louisiana State University and Agricultural and Mechanical College. Doktora Tezi.

I. Radu, D.Y. Li, R. Llewellyn. (2004). Tribological Behavior of Stellite 21 Modified with Yttrium. Wear, 257, 11541166.

Mottalebzadeh, A. (2015). High temperature wear performance of alloyed an carbide reinforced stellite 21 coatings. Doktora Tezi. İstanbul Teknik Üniversitesi. Fen Bilimleri Enstitüsü.

Necina, V., Pabst, W. (2019). Reduction of temperature gradient and carbon contamination in electric current assisted sintering (ECAS/SPS) using a "saw-tooth" heating Schedule. Ceramics International, 45.

Orru et al., 2009; Gullion et al., 2014; Chaim et al., 2018.

Reed R. C. (2006). The Superalloys Fundamentals and Applications. Cambridge University Press.

Rong, L. (2015) Jianhua Y., Qunli Z., Matthew X., Rachel C., Effects of molybdenum content on the wear/erosion and corrosion performance of low-carbon stellite alloys. Materials and Design, 78, 95-106.

Salehnasab B., Poursaeıdı E., Mortazavı S.A., Forkhıan G.H., (2016) Hot corrosion failure in the first stage nozzle of a gas turbine engine. Engineering Faülure Analysis 60.316-325.

Salvatore Grasso, Yoshio Sakka and Giovanni Maizza, 2009, Electric current activated/assisted sintering (ECAS): a review of patents 1906-2008. Science And Technology Of Advancedmaterials.

Torak, S. (2007). Gaz Türbin Kanatlarının Soğutulmasının Önemi ve Soğutma Yöntemlerinin İncelenmesi. Yüksek Lisans Tezi. Trakya Üniversitesi. Fen Bilimleri Enstitüsü.

Voort G.F.V., Manılova E.P., Lucas G.M. (2004), Metallographic Techniques for Superalloys. Microscopy and Microanalysis. 1-22.

Yuxiao W., Etienne B., Thomas S., Nabil T., Fadila K., Rejean R., Jolanta S., Myriam B. (2019). Thermal stability of a stellite/steel hardfacing interface during long-term aging. Materials Characterization, 154, 181-192. 